\section{Fatal central nervous system air embolism during elective esophagogastroduodenoscopy}

A 64-year-old woman with gastric adenocarcinoma and esophageal stricture underwent esophagogastroduodenscopy (EGD) and dilation. During the procedure no bleeding or mucosal tears were observed. She later appeared sedated but was unresponsive to naloxone. Physical examination revealed spontaneous eye opening with leftward gaze, autonomic instability, decerebrate posturing, myoclonus, absent gag reflex, and a positive Babinski sign.

Computed tomography (CT) scanning revealed air emboli in the right subcortical white matter and frontal lobe ( $\bullet$ Fig. 1 ). Transthoracic echocardiogram did not demonstrate a patent foramen ovale. The patient underwent emergent hyperbaric oxygen therapy; however, a repeat CT scan revealed massive cerebral edema with midline shift, and she died shortly afterwards.

A MEDLINE search through 2012 identified 16 cases of EGD-related pneumocephalus. Recommendations for prevention are elusive because of the infrequency of this complication [1]. Our review of the literature suggests an increased risk in patients with metastatic disease. Semierect positioning may predispose to infarction in the right hemisphere via the right common carotid artery [2]. Factors required for air embolism include a communication between the vasculature and the air source with a favorable pressure gradient $[1,3]$. Other proposed etiologic factors include fistulas, ulcers, damage secondary to biopsies, direct arterial or venous air introduction, and an intracardiac or intrapulmonary shunt $[1,4]$. It is impractical to screen for cardiac shunting as a patent foramen ovale is rarely found on autopsy $[1,5]$.

Central nervous system air emboli cause damage to vascular endothelium, cytotoxic edema, ischemia, and increased platelet aggregation. The clinical presentation de- pends on the site of embolization and the rate of air introduction [5]. The sensitivity of CT scanning for detecting air emboli declines over time because air is rapidly reabsorbed [4]. The treatment is hyperbaric oxygen therapy, the aim of which is compression of the gas emboli to decrease the duration of ischemia [2,4]. The mortality rate was at one time greater than $90 \%$; with hyperbaric therapy it is now $7 \%[1,3]$, although survivors often have considerable neurologic deficits.

Endoscopy_UCTN_Code_CPL_1AH_2AF

Competing interests: None

\section{K. Niehaus, E. Zamora, M. Harkins}

Dept. of Internal Medicine, University of New Mexico Health Sciences Center, Albuquerque, New Mexico, USA

\section{References}

1 Green BT, Tendler DA. Cerebral air embolism during upper endoscopy: case report and review. Gastrointest Endosc 2005; 61: 620-623

2 Akhtar N,Jafri W, Mozaffar T. Cerebral artery air embolism following an esophagogastroscopy: a case report. Neurology 2001; 56: $136-137$

3 LopezJC, Perez X, Esteve F. Cerebral air embolism during upper endoscopy. Endoscopy 2010; 42: E41

4 McAree BJ, Gilliland R, Campbell DM et al. Cerebral air embolism complicating esophagogastroduodenoscopy (EGD). Endoscopy 2008; 40: E191 -E192

5 Muth CM, Shank ES. Gas embolism. N Engl J Med 2000; 342: 476-482

\section{Bibliography}

DOI http://dx.doi.org/

10.1055/s-0033-1344328

Endoscopy 2013; 45: E205

(c) Georg Thieme Verlag KG

Stuttgart · New York

ISSN 0013-726X
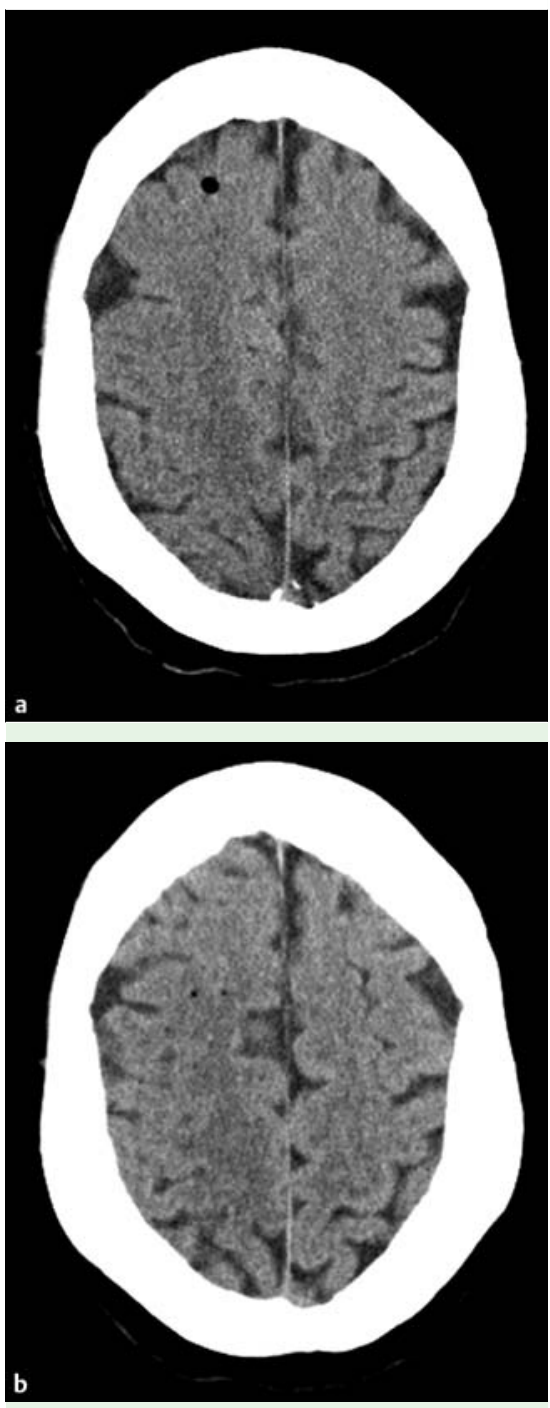

Fig. 1 Computed tomography (CT) images showing air in the brain parenchyma of the right cerebral hemisphere in an arterial distribution, consistent with an air embolus via the right internal carotid artery: $\mathbf{a}$ in the right frontal lobe; $\mathbf{b}$ in the right subcortical white matter.

Corresponding author

K. Niehaus, MD

University of New Mexico Health Sciences Center Dept. of Internal Medicine MSC10 5550

1 University of New Mexico

Albuquerque

NM 87131-0001

USA

Fax: +1-505-272-4628

kniehaus@salud.unm.edu 